\title{
Design of K-Band Substrate Integrated Waveguide Band-Pass Filter with High Rejection
}

\author{
Ahmed Rhbanou, Mohamed Sabbane \\ Department of Mathematics, FSM, Moulay Ismail University, Meknes, 50000, Morocco \\ E-mail: rhbanou@gmail.com \\ Seddik Bri \\ Material and Instrumentations group (M IN), Electrical Engineering Department, ESTM, Moulay Ismail \\ University, Meknes, 50000, Morocco, briseddik@gmail.com
}

\begin{abstract}
This article presents the design of K-band Substrate Integrated Waveguide (SIW) Band-pass filter with high rejection, by using the topology with iris and the SIW resonators. The simulated results of this filter have shown that the passband is from 17.3 GHz to $19.3 \mathrm{GHz}$, while the insertion loss is $1.35 \mathrm{~dB}$ within 10.9 \% bandwidth around $18.3 \mathrm{GHz}$ and input return loss in the passband is better than $15 \mathrm{~dB}$, with high rejection of $-57.88 \mathrm{~dB}$ at the frequency $24.07 \mathrm{GH}$. All the structures are designed on a single substrate of Rogers R04003 permittivity 3.55. The compatibility with planar circuits is provided via a specific microstrip transition (microstrip tapered transitions).
\end{abstract}

Index Terms - SIW cavity resonator, microwave filters, transition, SIWmicrostrip technology.

\section{INTRODUCTION}

A High selectivity, low insertion loss, small size and limited cost are so many essential questions in the design and the manufacturing of microwave circuits. Unfortunately, the traditional technology, either planar or non-planar, is incapable to provide all these characteristics at the same time. In fact, the rectangular waveguides present low insertion losses and good selectivity. However, their production is costly and their integration with other planar circuits requires a specific transition. For planar circuits have a low quality factor, but they have a good compatibility and low cost manufacturing. These constraints led us to use the SIW technology to combine the respective advantages of the technologies previously mentioned.

The SIW concept associates the use of planar technology microstrip and the functioning of cavities in which are going to exist volume modes. Technically, cavities are included in the substratum and are delimited for the upper and lower faces by the metal plane and for the side faces by rows of metallic holes. This vias have a diameter and spacing small to appear as electric walls [1]-[10].

The SIW (Substrate Integrated Waveguide) structures have been of great interest and with a specific transition that this technology is compatible with some planar technologies [11], [12]. The SIW has been applied successfully to the conception of planar compact components for the microwave and 
millimeter wave applications. Such as filters [13]-[17].

In this paper, the properties of the SIW bandpass filter in the K-band with iris topology are carefully studied in their equivalent circuit and their design. Then the equivalent circuit of SIW bandpass filter with high rejection was studied using the rules and conventional synthesis tools to define the coupling matrix of this filter. After defining the equivalent circuit, the second phase will be the study of the design, but before an important part will be devoted to resonators SIW, for produce the bandstop. The use of resonators and SIW bandpass filter allows the design of a filter having the peculiarity of offering a very high rejection located and close to the bandwidth. The simulations of the equivalent circuits were made by the method of moments (MoM) based on commercial software package (ADS). On the other hand the simulations of the structures were made by the finite element method (FEM) based on a commercial software package (HFSS). The results obtained by HFSS simulation are compared and discussed with the results in [18].

\section{DESIGN OF THE CAVITY RESONATOR SIW AND QUALITY FACTOR}

The propagation properties in the SIW and in the conventional metallic rectangular waveguide are very similar. In particular, the electromagnetic field distribution is $\mathrm{TE}_{101}$ [1], Thus, the initial dimensions of the SIW resonator cavity can be determined by the conventional resonant frequency formula of metallic waveguide resonator $\left(f_{\mathrm{c} 101}\right)$, where the length and width of the metallic cavity, $\mathrm{L}_{\mathrm{eff}}$ and $\mathrm{W}_{\text {eff }}$, should be replaced by the equivalent width $\mathrm{W}_{\text {SIW }}$ and length $\mathrm{L}_{\mathrm{SIW}}$ of the SIW cavity because of the presence of vias sidewall as shown in Fig. 1.

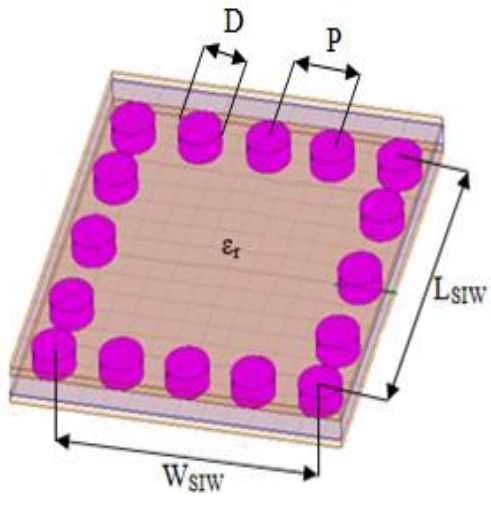

(a)

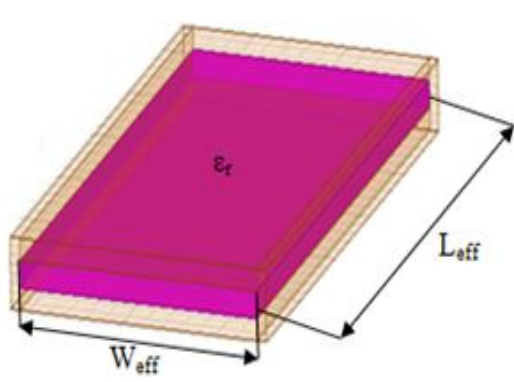

(b)

Fig. 1. (a) Cavity resonator SIW. (b) Rectangular cavity waveguide filled with dielectric.

A SIW cavity can be designed by using the relations 1,2 and 3 provided that $\mathrm{P}<\lambda_{0} *\left(\varepsilon_{\mathrm{r}} / 2\right)^{1 / 2}$ and $\mathrm{P}<4 * \mathrm{D}$ with $\varepsilon_{\mathrm{r}}$ relative permittivity, $\mathrm{D}$ and $\mathrm{P}$ are the diameter of the metallic via and the period of via holes respectively [2]-[9].

$$
\begin{gathered}
f_{c_{101}}=\frac{c}{2 \sqrt{\varepsilon_{r}}} \sqrt{\left(\frac{1}{W_{e f f}}\right)^{2}+\left(\frac{1}{L_{e f f}}\right)^{2}} \\
W_{\text {eff }}=W_{S I W}-\frac{D^{2}}{0.95 P}
\end{gathered}
$$




$$
L_{\text {eff }}=L_{S I W}-\frac{D^{2}}{0.95 P}
$$

The quality factor $\left(\mathrm{Q}_{\mathrm{pr}}\right)$ of a SIW cavity is presented by the following equation 4 [10]:

$$
\frac{1}{Q_{p r}}=\frac{1}{Q_{d}}+\frac{1}{Q_{c}}
$$

With $\left(\mathrm{Q}_{\mathrm{d}}\right)$ resulting from the power loss in the lossy dielectric material filling the cavity and $\left(\mathrm{Q}_{\mathrm{c}}\right)$ resulting from the power loss in the walls which have finite conductivity.

$$
\begin{aligned}
& Q_{d}=\frac{1}{\tan \delta} \\
& Q_{c}=\frac{\lambda_{r}}{\delta_{s}} F
\end{aligned}
$$

Where $(\tan \delta)$ is the loss tangent of the dielectric, $(\lambda r)$ is the free-space wavelength in the dielectric to the cavity resonant frequency and $(\delta \mathrm{s})$ is called the skin depth. $(\mathrm{F})$ is the shape factor of the SIW cavity, for resonance in $\mathrm{TE}_{101}$ mode, the expression of $(\mathrm{F})$ is given by equation 7 .

$$
F=\frac{W_{S I W} L_{S I W} h}{2} \frac{\left(\frac{1}{W_{S I W}^{2}}+\frac{1}{h^{2}}\right)^{3 / 2}}{\frac{h}{W_{S I W}{ }^{2}}\left(W_{S I W}+2 L_{S I W}\right)+\frac{W_{S I W}}{h^{2}}\left(h+2 L_{S I W}\right)}
$$

The parameters $\mathrm{W}_{\mathrm{SIW}}, \mathrm{L}_{\mathrm{SIW}}$ and $\mathrm{h}$ are respectively the width, the length and the height of the SIW cavity.

\section{THEORETICAL STUDY OF BAND PASS FILTER AND PROPOSED TRANSITIONS}

Generally, the microstrip transitions are very required to combine SIW and microstrip technologies. Tapered transition shown in Fig. 2 has been studied. This kind of transition consists of a tapered microstrip line section that connects a 50 microstrip line and the integrated waveguide. The physical characteristics of microstrip line (the width $\mathrm{W}_{\mathrm{M}}$ ) and the dimensions (width $\mathrm{W}_{\mathrm{T}}$ and length $\mathrm{L}_{\mathrm{T}}$ ) of a transition are widely detailed in [11], [12].

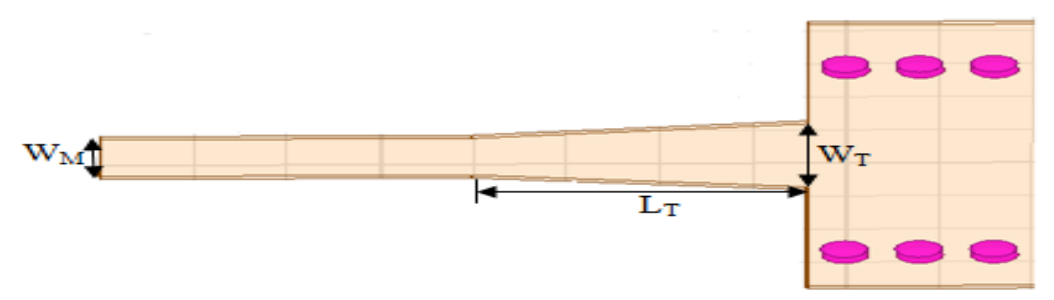

Fig. 2. SIW Guide with tapered transitions.

The microwave band-pass filters are presented by an equivalent circuit [13]. This circuit consists of impedance inverters and parallel resonant circuits. The number of the resonators or the order of the filter $(\mathrm{N})$ is determined by equation 8 applicable in the case of Chebyshev synthesis [13]. With $\mathrm{L}_{\mathrm{As}}$ is the level of out-of-band rejection in the pulsation $\Omega_{\mathrm{s}}$ and $\mathrm{L}_{\mathrm{Ar}}$ is the maximal amplitude of the undulation. $\Omega_{\mathrm{s}}$ is the frequency of rejection high, found by the equation of the transformation of 
frequency [13], whose cut-off frequency is $\Omega_{\mathrm{c}}=1 \mathrm{rad} / \mathrm{s}$.

$$
N \geq \frac{\cosh ^{-1} \sqrt{\frac{10^{0.1} L_{A s}-1}{10^{0.1} L_{A r}-1}}}{\cosh ^{-1} \Omega_{S}}
$$

The resonators in equivalent circuit are modeled by inductance and capacitance in series [13]. The coupling coefficients between resonators are provided by impedance inverters $\mathrm{K}_{\mathrm{i}, \mathrm{i}+1}(0 \leq \mathrm{i} \leq \mathrm{n})$ [13], so the filter coupling matrix is presented in following form:

$S$
1
2
$\cdots$
$\cdots+1$
$\cdots$
$n$
$L$
$L$$\left(\begin{array}{cccccccc}0 & K_{0.1} & 0 & 0 & 0 & 0 & 0 & 0 \\ K_{0.1} & 0 & K_{1.2} & 0 & 0 & 0 & 0 & 0 \\ 0 & K_{1.2} & 0 & \ldots . & 0 & 0 & 0 & 0 \\ 0 & 0 & \ldots . . & 0 & K_{i . i+1} & 0 & 0 & 0 \\ 0 & 0 & 0 & K_{i . i+1} & 0 & \ldots . & 0 & 0 \\ 0 & 0 & 0 & 0 & \ldots . & 0 & K_{n-1 . n} & 0 \\ 0 & 0 & 0 & 0 & 0 & K_{n-1 . n} & 0 & K_{n \cdot n+1} \\ 0 & 0 & 0 & 0 & 0 & 0 & K_{n . n+1} & 0\end{array}\right)$

Fig. 3. Coupling matrix of the microwave bandpass filter circuit.

The indices $\mathrm{S}$ and $\mathrm{L}$ correspond to the source and to the load respectively, in other words to the accesses. The indices going from 1 to $\mathrm{n}$ correspond to the resonators.

On the other the waveguide filters are formed with resonator distributed elements interconnected by impedance inverters or admittance. The equivalent circuit of the band-pass filter SIW is presented by impedance inverter and phase shifts [14]. The impedance inverters $\mathrm{K}_{\mathrm{i}, \mathrm{i}+1}(0 \leq \mathrm{i} \leq \mathrm{n})$ are given by the formulas in [15].

The SIW filter with iris is influenced by the lengths $\mathrm{L}_{\text {SIW }}(\mathrm{i}=1,2,3 \ldots, \mathrm{n})$ the resonators and also by the coupling, That is an opening in the wall between two adjacent cavities. This type of opening is called iris (the widths $\mathrm{W}_{\mathrm{SIWi}}(\mathrm{i}=0,1,2 \ldots . . \mathrm{n})$ the resonators), as illustrated in Fig. 4.

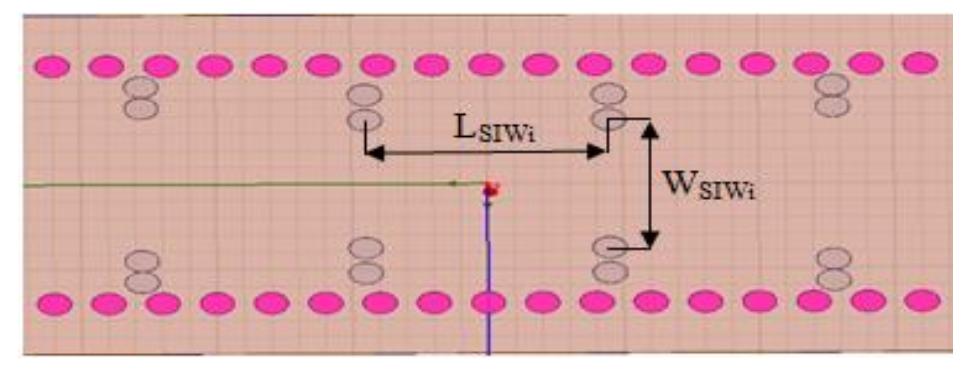

Fig. 4. SIW filter with iris.

The widths $\mathrm{W}_{\text {SIW }}(\mathrm{i}=0,1,2 \ldots . . \mathrm{n})$ of the resonators in SIW technology are determined by the abacus of the estimated width in rectangular waveguide [16]. The lengths $\mathrm{L}_{\mathrm{SIWi}}(\mathrm{i}=1,2,3, \ldots \mathrm{n})$ the resonators are determined by the formulas in [17]. 


\section{RESULTS}

\section{A. SIW filter with inductive post-wall irises in the K-band}

In this work, all the structures are designed on a single substrate of Rogers R04003 permittivity $\varepsilon_{\mathrm{r}}$ $=3.55$ and height $\mathrm{h}=0.508 \mathrm{~mm}$.

Generally to determine the parameters of SIW guide, designed in the K-band [15-22] GHz from a conventional wave guide with dimensions $\mathrm{a}=12.954 \mathrm{~mm}$ and $\mathrm{b}=6.477 \mathrm{~mm}$, using the formulas given by equations 1,2 and 3 for mode $\mathrm{TE}_{10}$. With the diameter of the metallic via $\mathrm{D}=0.5 \mathrm{~mm}$ and the period of the vias $\mathrm{P}=1 \mathrm{~mm}$. Following this approach, the distance between the rows of the centres of via is $\mathrm{W}_{\mathrm{SIW}}=7.13 \mathrm{~mm}$ and the length of SIW guide is $\mathrm{L}_{\mathrm{SIW}}=\mathrm{L}_{\text {eff }}=80 \mathrm{~mm}$ because does not bring significant change in the propagation phenomenon.

A microstrip transition (taper) is used to interconnect SIW to the planar transmission lines. There is a tapered section which is used to match the impedance between a $50 \Omega$ microstrip line and the SIW. The $50 \Omega$ microstrip line, in which the dominant mode is quasi-TEM, can excite well the dominant mode $\mathrm{TE}_{10}$ of the SIW, as their electric field distributions are approximate in the profile of the structure.

The dimensions of the transition and the microstrip line $\operatorname{are~} \mathrm{W}_{\mathrm{M}}=1.13, \mathrm{~W}_{\mathrm{T}}=2.4 \mathrm{~mm}$ and $\mathrm{L}_{\mathrm{T}}=14.565$ $\mathrm{mm}$. A schematic view of a SIW with two tapered transitions is shown in Fig. 5.

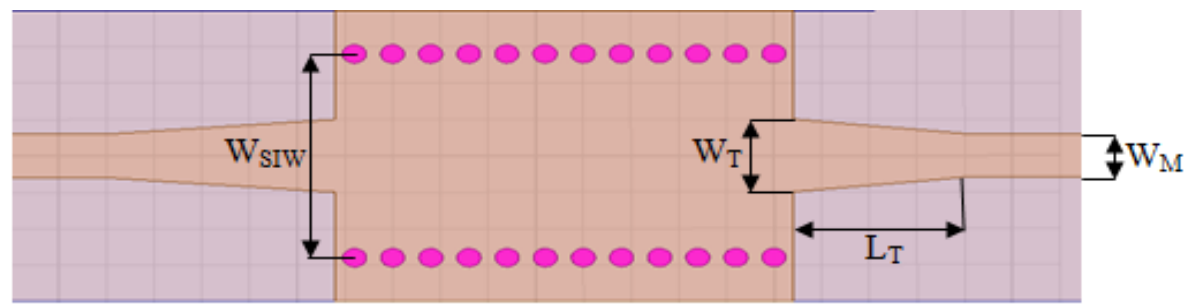

Fig. 5. SIW with two tapered transitions.

This structure is simulated by using HFSS. The simulated S-parameters of SIW with two tapered transitions in the frequency band [15-22] GHz are shown in Fig. 6.

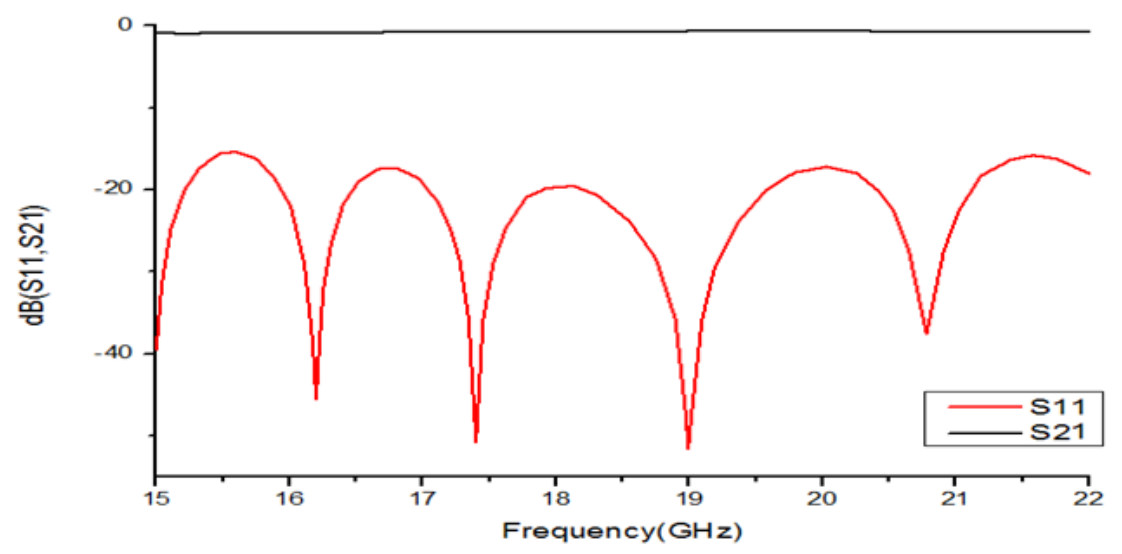

Fig. 6. Frequency response of SIW with two tapered transitions.

The results illustrated in Fig. 6, indicate that the reflection coefficient S11 remains below $-15 \mathrm{~dB}$ across the entire band and the transmission coefficient $\mathrm{S} 21$ is around $0.8 \mathrm{~dB}$.

Before passing to the design of SIW filter iris in the K-band, by studying their equivalent circuit, by 
using software 2D simulation (ADS). This filter has a centre frequency $\mathrm{f}_{0}=18.35 \mathrm{GHz}$, the absolute bandwidth $2 \mathrm{GHz}$ and the relative bandwidth $\mathrm{FBW}=10.9 \%$, the ripple is $0.01 \mathrm{~dB}$. The filter must submit a rejection of $-20 \mathrm{~dB}$ at $20.8 \mathrm{GHz}$. Therefore, a $4^{\text {rd }}$ degree SIW filter, the circuit model of microwave filter in ADS is shown in Fig. 7.

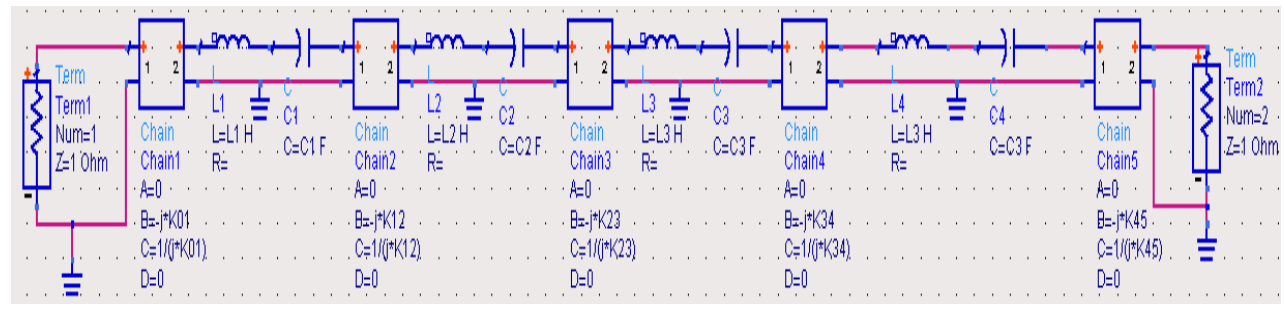

Fig. 7. Circuit model of microwave filter in ADS.

$\mathrm{K}_{0.1}$ and $\mathrm{K}_{4.5}$ correspond to access coupling coefficients, $\mathrm{K}_{1.2}, \mathrm{~K}_{2.3}$ and $\mathrm{K}_{3.4}$ correspond the coupling coefficients between resonators. The function tuning of ADS is used to enable adjustment of the coupling coefficients $\mathrm{K}_{\mathrm{i}, \mathrm{i}+1}(0 \leq \mathrm{i} \leq 4)$. Finally, the coupling matrix is shown in Fig. 8 .

\begin{tabular}{|c|c|c|c|c|c|c|}
\hline & $S$ & 1 & 2 & 3 & 4 & $L$ \\
\hline$S$ & 0 & 0.354 & 0 & 0 & 0 & 0 \\
\hline 1 & 0.354 & 0 & 0.088 & 0 & 0 & 0 \\
\hline 2 & 0 & 0.088 & 0 & 0.061 & 0 & 0 \\
\hline 3 & 0 & 0 & 0.061 & 0 & 0.088 & 0 \\
\hline 4 & 0 & 0 & 0 & 0.088 & 0 & 0.354 \\
\hline$I$ & 0 & 0 & 0 & 0 & 0.354 & 0 \\
\hline
\end{tabular}

Fig. 8. Coupling matrix of the microwave bandpass filter circuit.

The indices $\mathrm{S}$ and $\mathrm{L}$ correspond to the source and to the load respectively, in other words to the accesses. The indices going from 1 to 4 correspond to the four resonators. The ideal frequency response circuit in the K-band is shown in Fig. 9.

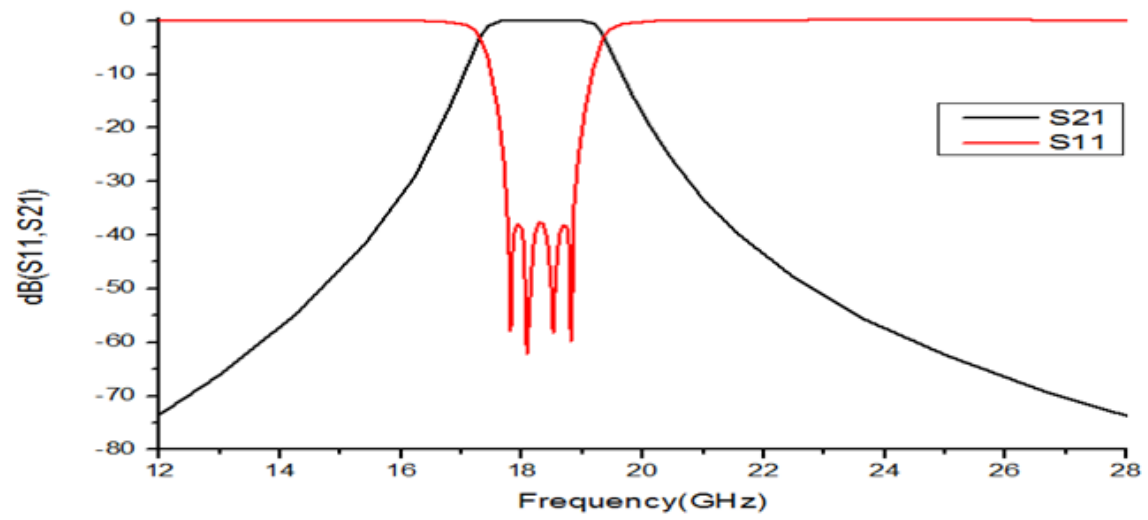

Fig. 9. Ideal frequency response of the model circuit in ADS.

The result simulated by ADS in Fig. 9, shows that the full frequency passband is from 17.3 to 19.3 GHz. the center frequency $\mathrm{f}_{0}=18.3 \mathrm{GHz}$, the absolute bandwidth $2 \mathrm{GHz}$ and the relative bandwidth FBW $=10.9 \%$. The return loss is better than $20 \mathrm{~dB}$ between $17.64 \mathrm{GHz}$ and $18.98 \mathrm{GHz}$. You can be seen that the filter respects well the tender specifications.

After the study of equivalent circuit of SIW filter iris in the K-band, passing to the design, by using 
the Rogers R04003 substrate for comparing with the results in [18]. The structure of SIW bandpass filter in the K-band with iris topology a $4^{\text {rd }}$ order is shown in Fig. 10.

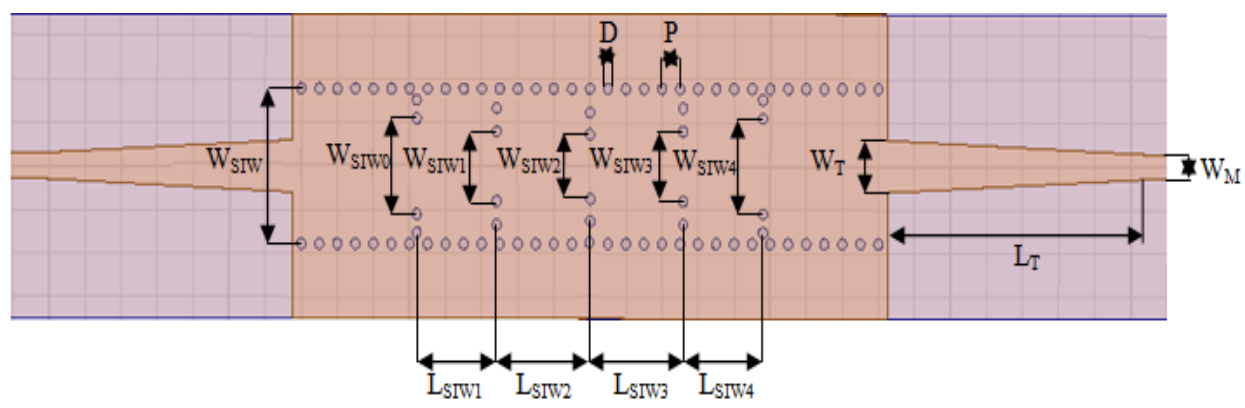

Fig. 10. SIW filter with stepped transition using post-wall irises.

Using the method of the abacus, to find the results which are going to be optimized by HFSS, the final dimensions of the structure are: $\mathrm{L}_{\mathrm{SIW} 1}=\mathrm{L}_{\mathrm{SIW} 4}=4.43 \mathrm{~mm}, \mathrm{~L}_{\mathrm{SIW} 2}=\mathrm{L}_{\mathrm{SIW}}=5.17 \mathrm{~mm}, \mathrm{~W}_{\mathrm{SIW}_{0}}=\mathrm{W}_{\mathrm{SIW}_{4}}=4.4$ $\mathrm{mm}, \mathrm{W}_{\mathrm{SIW} 1}=\mathrm{W}_{\mathrm{SIW}_{3}}=3.2 \mathrm{~mm}, \mathrm{~W}_{\mathrm{SIW}_{2}}=2.94, \mathrm{~W}_{\mathrm{T}}=2.4 \mathrm{~mm}, \mathrm{~L}_{\mathrm{T}}=14.565 \mathrm{~mm}, \mathrm{D}=0.5 \mathrm{~mm}, \mathrm{P}=1 \mathrm{~mm}, \mathrm{~W}_{\mathrm{SIW}}$ $=7.13 \mathrm{~mm}, \mathrm{~W}_{\mathrm{M}}=1.13 \mathrm{~mm}$. Fig. 11 illustrated the reflection coefficient $\mathrm{S} 11$ and the transmission coefficient S21 of SIW bandpass filter in the K-band with iris and also the results in [18].

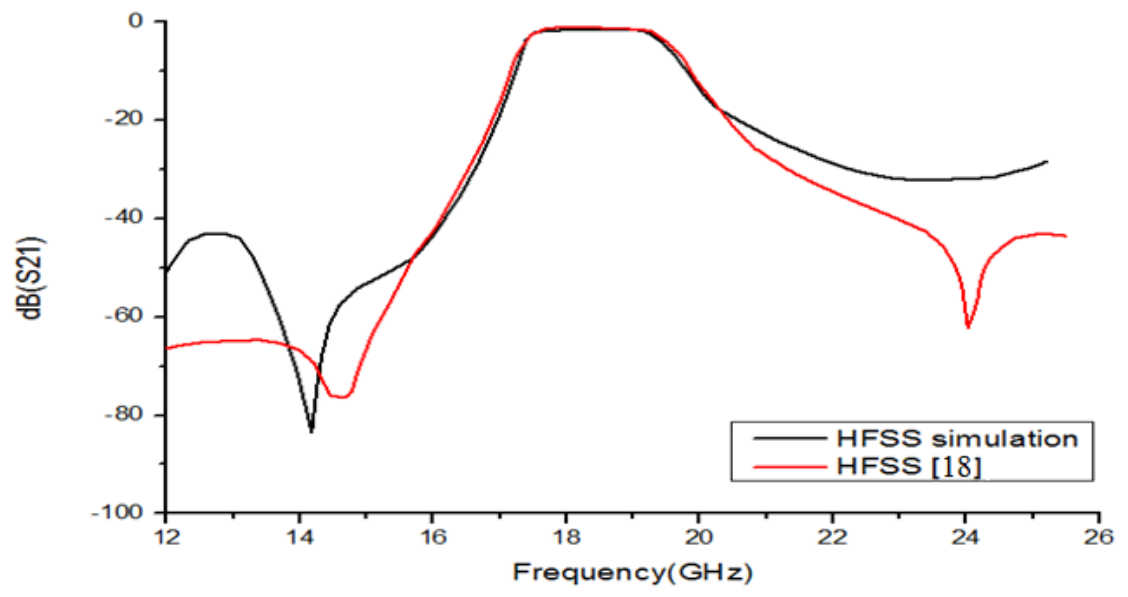

(a)

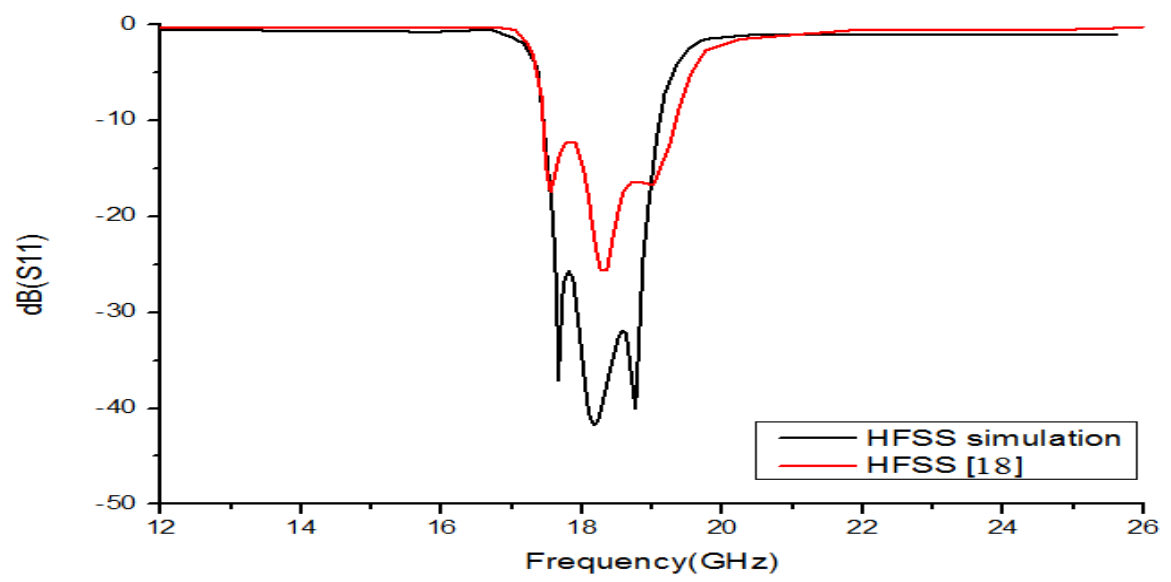

(b)

Fig. 11. Frequency response of SIW bandpass filter with iris. (a) Transmission coefficient S21 as a function of frequency. (b) Reflection coefficient S11 as a function of frequency. 
The result simulated by HFSS shows that the full frequency passband is from 17.3 to $19.2 \mathrm{GHz}$. the center frequency $\mathrm{f}_{0}=18.25 \mathrm{GHz}$, the absolute bandwidth $1.9 \mathrm{GHz}$ and the relative bandwidth $\mathrm{FBW}=10.4 \%$. The insertion loss around $18.25 \mathrm{GHz}$ is approximately $1.3 \mathrm{~dB}$, the return loss in the passband is better than $20 \mathrm{~dB}$ between $17.56 \mathrm{GHz}$ and $18.87 \mathrm{GHz}$.

On the other side, the result simulated by HFSS in [18] shows that the full frequency passband is from 17.3 to $19.3 \mathrm{GHz}$. the center frequency $\mathrm{f}_{0}=18.3 \mathrm{GHz}$, the absolute bandwidth $2 \mathrm{GHz}$ and the relative bandwidth $\mathrm{FBW}=10.9 \%$. The insertion loss around $18.3 \mathrm{GHz}$ is approximately $1.3 \mathrm{~dB}$, the return loss in the passband is $10 \mathrm{~dB}$, with high rejection of $-57.88 \mathrm{~dB}$ at the frequency $24.07 \mathrm{GHz}$.

Both results are in good agreement, but the result simulated by HFSS in [18] shows a high rejection, because of the use of resonators SIW.

\section{B. Equivalent circuit SIW bandpass filter in the K-band with high rejection}

The equivalent circuit of SIW filter in the K-band is realized (Fig. 7). For to have an rejection in $24.07 \mathrm{GHz}$, using the same (LC) resonators as the other resonators, which model the absorption cavities dimensioned to resonate at frequencies to reject $(24.07 \mathrm{GHz})$ and added to the filter, the frequencies to be rejected are adjusted using the chord elements that model a parallel reactance. Moreover, each resonator receives a parallel reactance, to adjust their resonant frequency after adding the absorption resonators. Modeling circuit of this modification, with the addition of a resonator in parallel and coupled to the latter by an impedance inverter is shown in Fig. 12. 


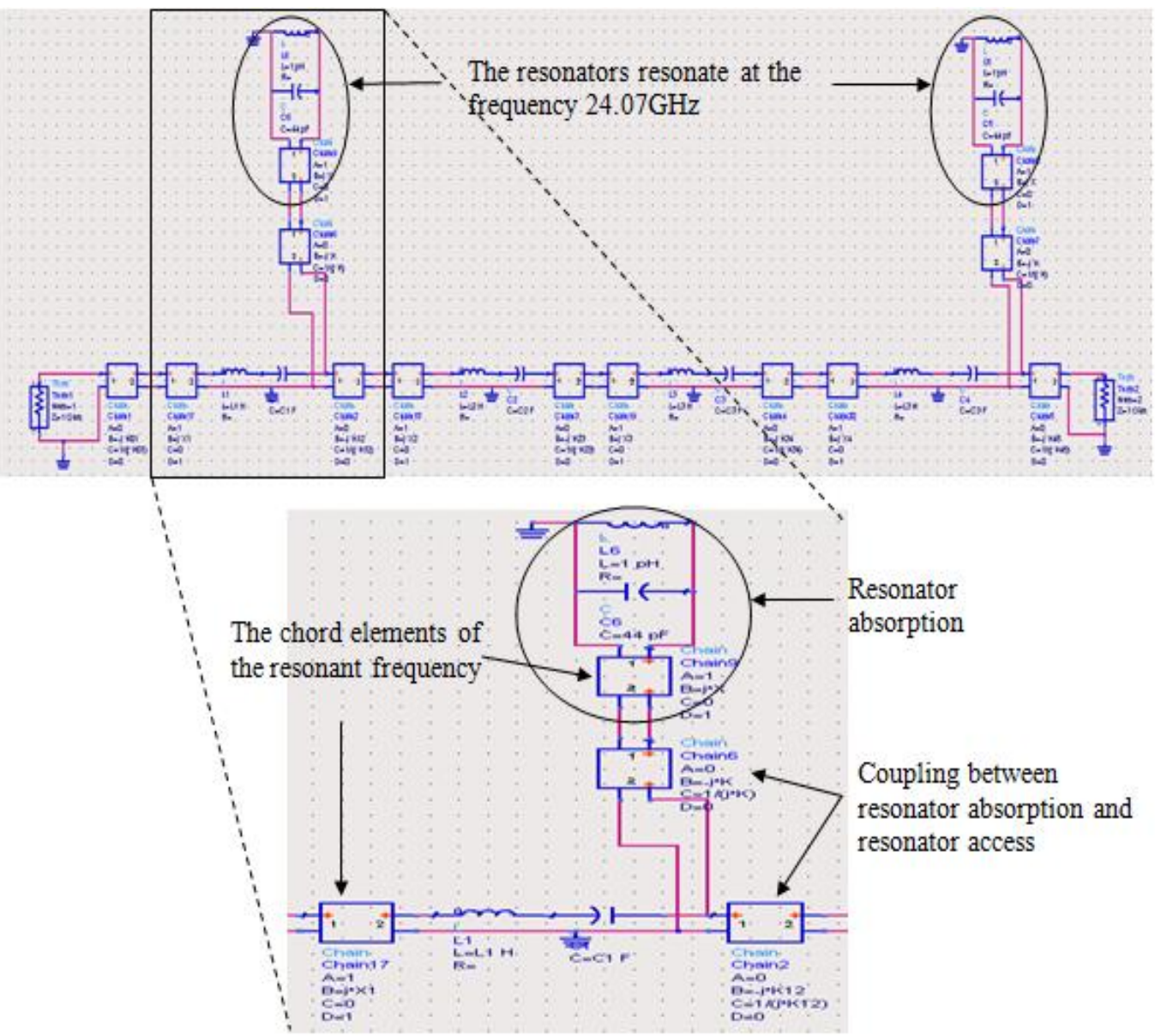

Fig. 12. Circuit model of SIW filter with resonators absorption.

The ADS tuning tool will be called upon to adjust the various settings that are the coupling coefficients and the parallel reactors, for obtain the coupling matrix shown in Fig. 13.

\begin{tabular}{|c|c|c|c|c|c|c|c|c|}
\hline & $S$ & BSRC 1 & 1 & 2 & 3 & 4 & BSRC & $2 \quad L$ \\
\hline$S$ & 0 & 0 & 0.354 & 0 & 0 & 0 & 0 & 0 \\
\hline BSRC 1 & 0 & 38 & 4.58 & 0 & 0 & 0 & 0 & 0 \\
\hline 1 & 0.354 & 4.58 & -0.014 & 0.088 & 0 & 0 & 0 & 0 \\
\hline 2 & 0 & 0 & 0.088 & -0.014 & 0.061 & 0 & 0 & 0 \\
\hline 3 & 0 & 0 & 0 & 0.061 & -0.011 & 0.088 & 0 & 0 \\
\hline 4 & 0 & 0 & 0 & 0 & 0.088 & -0.011 & 4.58 & 0.354 \\
\hline $\begin{array}{lll}B S R C & 2\end{array}$ & 0 & 0 & 0 & 0 & 0 & 4.58 & 38 & 0 \\
\hline$L$ & 0 & 0 & 0 & 0 & 0 & 0.354 & 0 & 0 \\
\hline
\end{tabular}

Fig. 13. Coupling matrix of the microwave bandpass filter circuit integrating absorption resonators.

BSRC1 and BSRC2 correspond to the two resonators absorption (Band-Stop Resonator Cavity), they resonate at the frequency of $24.07 \mathrm{GHz}$, the diagonal elements corresponding to the absorption resonators. The circuit frequency response is shown in Fig. 14. 


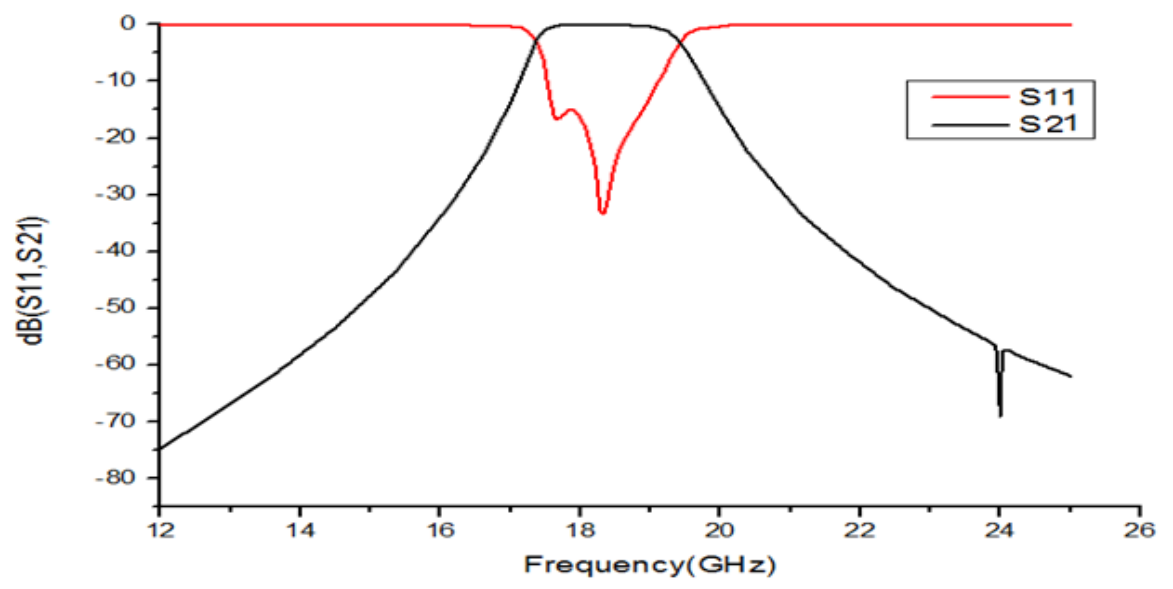

Fig. 14. Frequency response of the circuit model.

The result simulated by ADS in Fig. 14, shows that the full frequency passband is from $17.3 \mathrm{GHz}$ to 19.3 GHz. the center frequency $\mathrm{f}_{0}=18.3 \mathrm{GHz}$, the absolute bandwidth $2 \mathrm{GHz}$ and the relative bandwidth FBW= $10.9 \%$. The return loss is better than $15 \mathrm{~dB}$ between $17.61 \mathrm{GHz}$ and $18.86 \mathrm{GHz}$, with high rejection of $-68 \mathrm{~dB}$ at the frequency $24 \mathrm{GHz}$.

\section{Configuration of the resonators SIW}

The design of a filter having the peculiarity to offer a very high rejection located and close to the bandwidth, needs to use the resonators for to produce the bandstop response.

A square cavity ( $\mathrm{W}_{\text {eff }}=\mathrm{L}_{\text {eff }}$ ) in $\mathrm{TE}_{101}$ mode, allows it away to the parasitic modes in the spectrum. The width and the length of the cavity resonator SIW are $\mathrm{W}_{\mathrm{SIW}}=\mathrm{L}_{\mathrm{SIW}}=4.7 \mathrm{~mm}$, with the dimensions of the transition and the microstrip line are: $\mathrm{W}_{\mathrm{M}}=1.13, \mathrm{~W}_{\mathrm{T}}=2.4 \mathrm{~mm}$ and $\mathrm{L}_{\mathrm{T}}=14.565 \mathrm{~mm}$, the quality factor $\left(\mathrm{Q}_{\mathrm{pr}}\right)$ of this cavity resonator SIW is 370 .

The structure and the dimensions of the cavity resonator SIW with two tapered transitions are shown in Fig. 15.

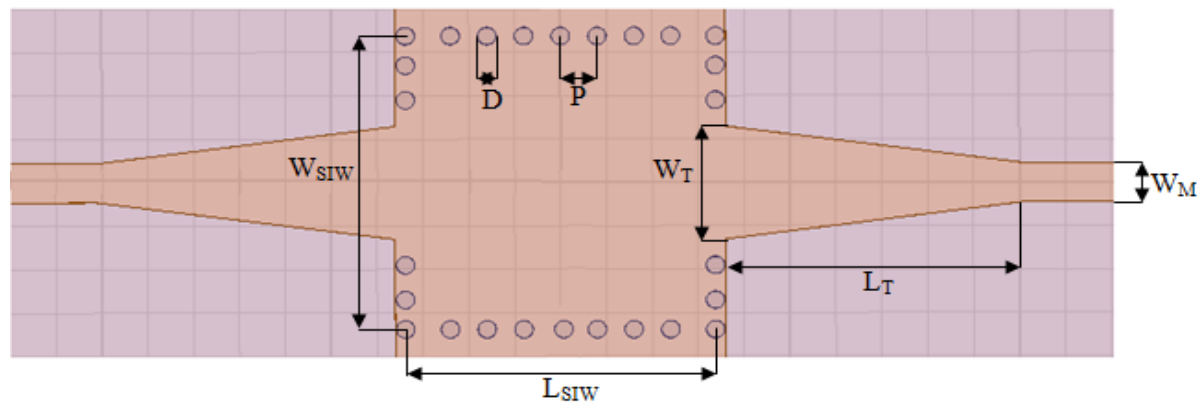

Fig. 15. Resonator SIW with two tapered transitions.

The transmission coefficient S21 and the reflection coefficient S11 of the cavity resonator SIW with two tapered transitions are shown in Fig. 16. 


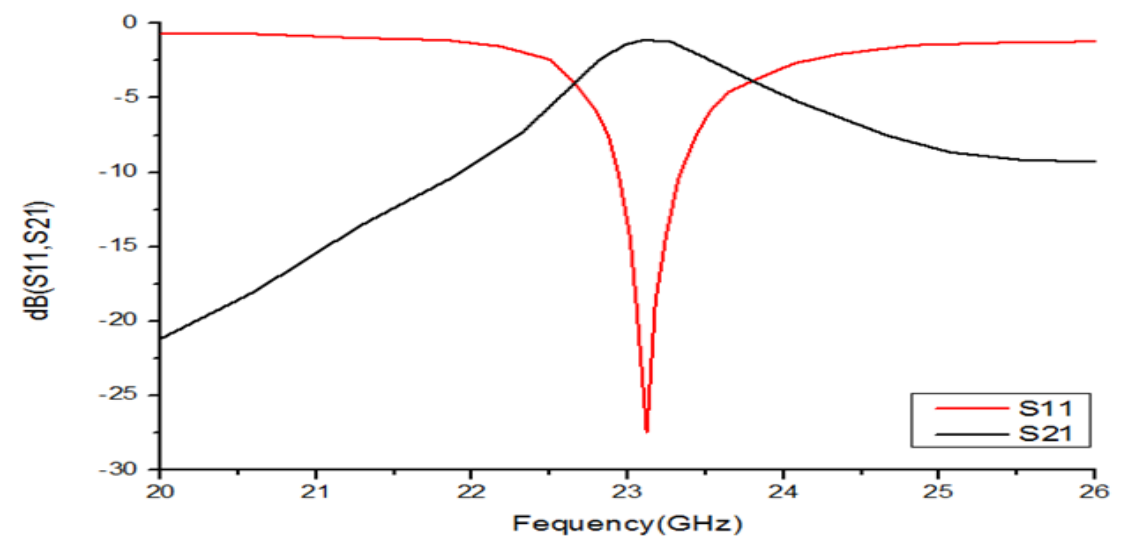

Fig. 16. Frequency response of resonator SIW with two tapered transitions.

The simulation of the resonator SIW in Fig. 16 showed that the resonance frequency was at 23.12 GHz. After studying the cavity resonator SIW bandpass, passing the bandstop response, by using a SIW guide connects to the cavity resonator SIW (Fig. 17).

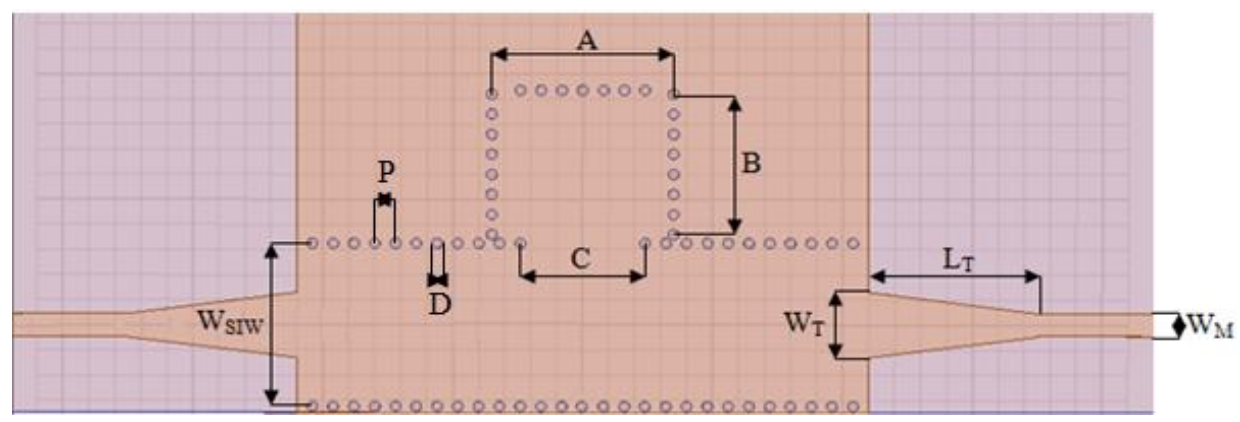

Fig. 17. Configuration of cavity resonator SIW bandstop with two tapered transitions.

Where (B) and (A) are the width and the length of SIW cavity that affects the bandstop response, the value (C) is the input length of resonator. To reach the $24.07 \mathrm{GHz}$ by varying the width of the cavity while the rest of the dimensions are being kept constant.

The transmission coefficient S21 of resonator SIW bandstop is shown in Fig. 18, for the values of the width (B) equal to $4.7 \mathrm{~mm}, 3.435 \mathrm{~mm}$ and $2.935 \mathrm{~mm}$ respectively, with the length (A) and the other dimensions are constant $\left(\mathrm{D}=0.5 \mathrm{~mm}, \mathrm{P}=1 \mathrm{~mm}, \mathrm{~W}_{\mathrm{M}}=1.13, \mathrm{~W}_{\mathrm{T}}=2.4 \mathrm{~mm}, \mathrm{~L}_{\mathrm{T}}=14.565 \mathrm{~mm}, \mathrm{C}=4\right.$ $\mathrm{mm}, \mathrm{A}=4.7 \mathrm{~mm})$. 


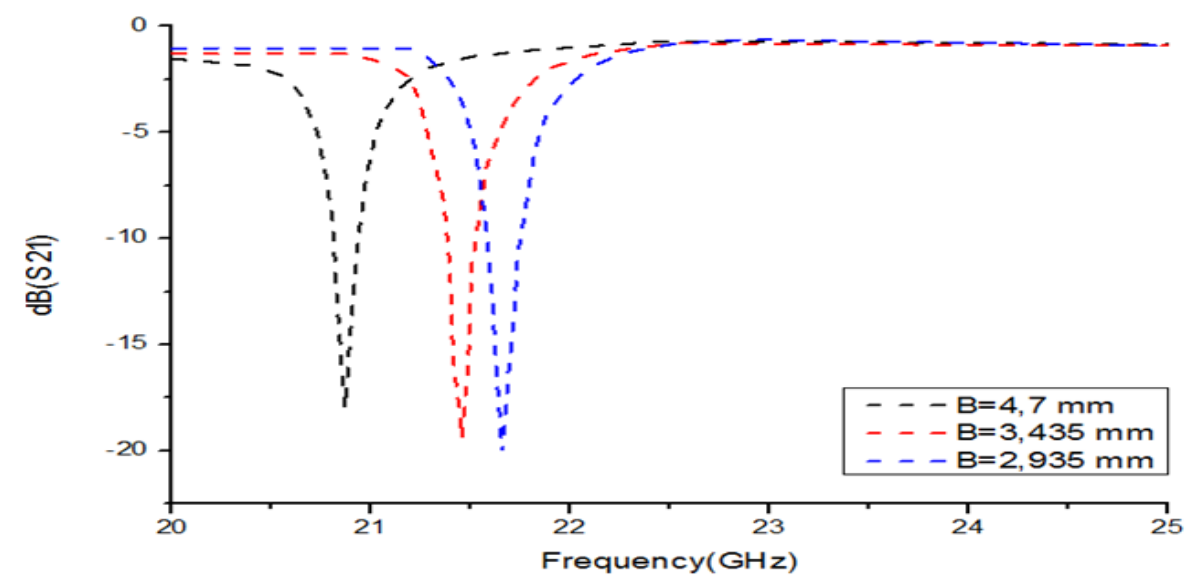

Fig. 18. Transmission coefficient S21 as a function of frequency of variation of (B) for the resonator SIW bandstop with two tapered transitions with dimensions $\mathrm{D}=0.5 \mathrm{~mm}, \mathrm{P}=1 \mathrm{~mm}, \mathrm{~W}_{\mathrm{M}}=1.13 \mathrm{~mm}, \mathrm{~W}_{\mathrm{T}}=2.4 \mathrm{~mm}, \mathrm{~L}_{\mathrm{T}}=14.565 \mathrm{~mm}, \mathrm{C}=4 \mathrm{~mm}$, $\mathrm{A}=4.7 \mathrm{~mm}$.

The results simulated by HFSS of resonator SIW bandstop in three different values of the width (B) are shown in Table 1.

TABLE I. FREQUENCY RESPONSE OF VARIATION OF (B) FOR RESONATOR SIW BANDSTOP WITH DIMENSIONS D $=0.5 \mathrm{MM}, \mathrm{P}=1 \mathrm{MM}$, $\mathrm{W}_{\mathrm{M}}=1.13, \mathrm{~W}_{\mathrm{T}}=2.4 \mathrm{MM}, \mathrm{L}_{\mathrm{T}}=14.565 \mathrm{MM}, \mathrm{C}=4 \mathrm{MM}, \mathrm{A}=4.7 \mathrm{MM}$

\begin{tabular}{ccccc}
\hline B $(\mathbf{m m})$ & Centre Stopband Frequency $(\mathbf{G H z})$ & Attenuation(dB) & 3dB Stopband Bandwidth $(\mathbf{G H z})$ & insertion loss $(\mathbf{d B})$ \\
\hline 4.7 & 20.88 & -18.28 & 20.7 to 21 & 2.06 \\
3.435 & 21.46 & -19.8 & 21.26 to 21.7 & 1.64 \\
2.935 & 21.67 & -20.13 & 21.44 to 21.92 & 1.38 \\
\hline
\end{tabular}

The results show that a decrease in the width (B) a resulted in an increase in the centre stopband frequency and stopband bandwidth, by against the attenuation and insertion loss are decreased.

A single cavity is not sufficient to expect the frequency $24.07 \mathrm{GHz}$. using two resonators of the same dimensions, the model of the structure is shown in Fig. 19.

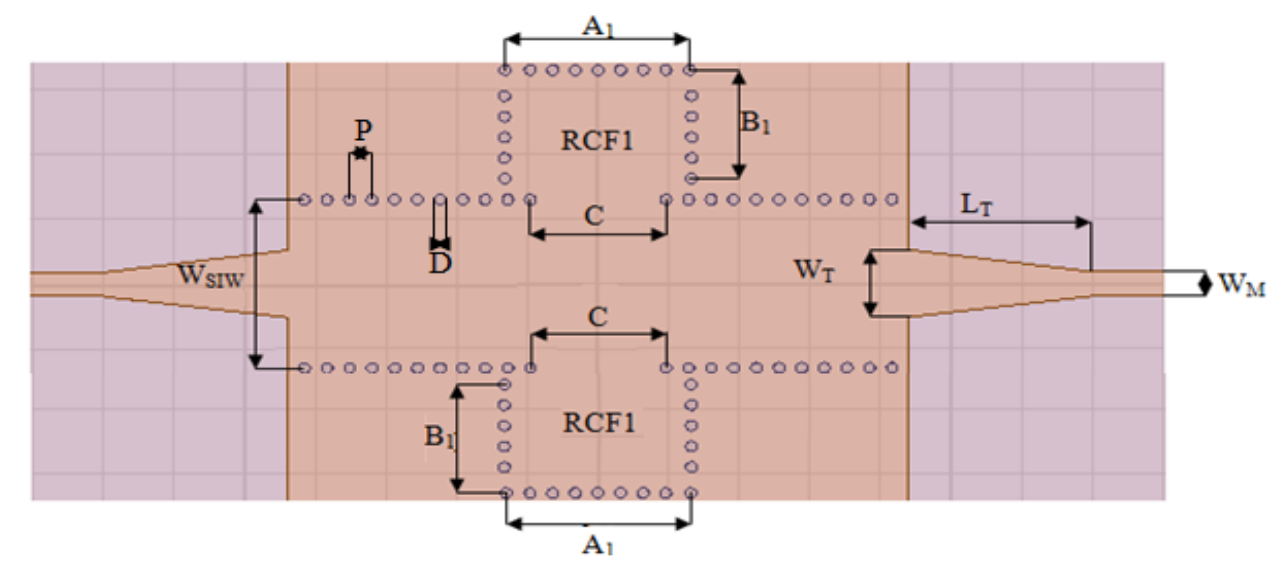

Fig. 19. Configuration of cavity resonator SIW bandstop with two tapered transitions.

The dimensions of the structure are: $\mathrm{D}=0.5 \mathrm{~mm}, \mathrm{P}=1 \mathrm{~mm}, \mathrm{~W}_{\mathrm{M}}=1.13, \mathrm{~W}_{\mathrm{T}}=2.4 \mathrm{~mm}, \mathrm{~L}_{\mathrm{T}}=14.565$ $\mathrm{mm}, \mathrm{A}_{1}=4.7 \mathrm{~mm}$ and $\mathrm{B}_{1}=2.935 \mathrm{~mm}$, with the input length of resonator is $\mathrm{C}=4 \mathrm{~mm}$.

The transmission coefficient S21 and the reflection coefficient S11 of the cavity resonator SIW bandstop with two tapered transitions are shown in Fig. 20. 


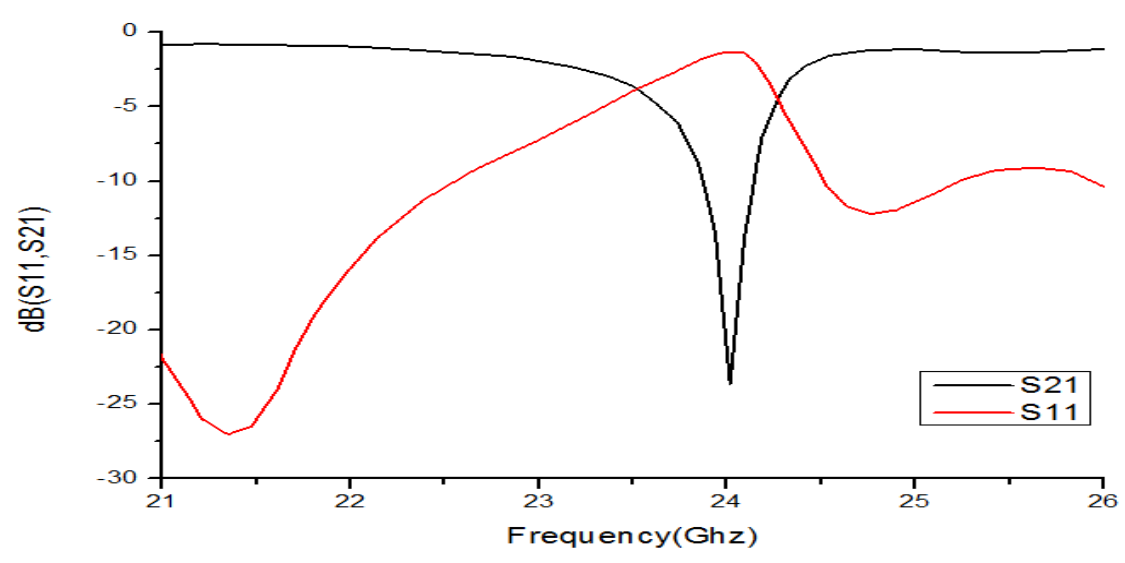

Fig. 20. Frequency response of resonator SIW bandstop with two tapered transitions.

The result obtained by Fig. 20, shows that the resonance frequency is $24.07 \mathrm{GHz}$.

\section{Design of SIW bandpass filter in the K-band with high rejection}

After designing the SIW filter in the K-band and the resonators SIW stopband, by combining the two structures for to have a SIW bandpass filter in the K-band with high rejection, the structure is shown in Fig. 21.

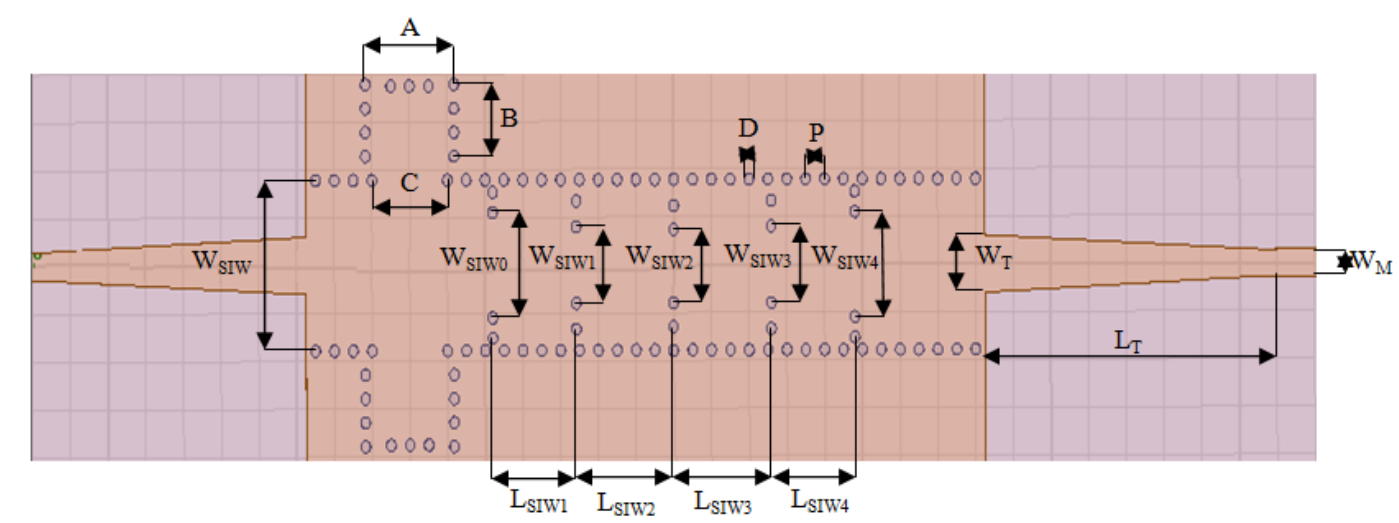

Fig. 21. SIW bandpass filter iris in the K-band with high rejection.

The final dimensions of the structure are:

$\mathrm{L}_{\mathrm{SIW} 1}=\mathrm{L}_{\mathrm{SIW} 4}=4.43 \mathrm{~mm}, \mathrm{~L}_{\mathrm{SIW} 2}=\mathrm{L}_{\mathrm{SIW} 3}=5.17 \mathrm{~mm}, \mathrm{~W}_{\mathrm{SIW} 0}=\mathrm{W}_{\mathrm{SIW}_{4}}=4.4 \mathrm{~mm}, \mathrm{~W}_{\mathrm{SIW}_{1}}=\mathrm{W}_{\mathrm{SIW}_{3}}=3.2 \mathrm{~mm}$, $\mathrm{W}_{\mathrm{SIW} 2}=2.94, \mathrm{~W}_{\mathrm{T}}=2.4 \mathrm{~mm}, \mathrm{~L}_{\mathrm{T}}=14.565 \mathrm{~mm}, \mathrm{D}=0.5 \mathrm{~mm}, \mathrm{P}=1 \mathrm{~mm}, \mathrm{~W}_{\mathrm{SIW}}=7.13 \mathrm{~mm}, \mathrm{~W}_{\mathrm{M}}=1.13 \mathrm{~mm}$, $\mathrm{A}=4.7 \mathrm{~mm}, \mathrm{~B}=2.935 \mathrm{~mm}$ and $\mathrm{C}=4 \mathrm{~mm}$.

Fig. 22 illustrated the reflection coefficient S11 and the transmission coefficient S21 of SIW bandpass filter iris with high rejection and also the results in [18]. 


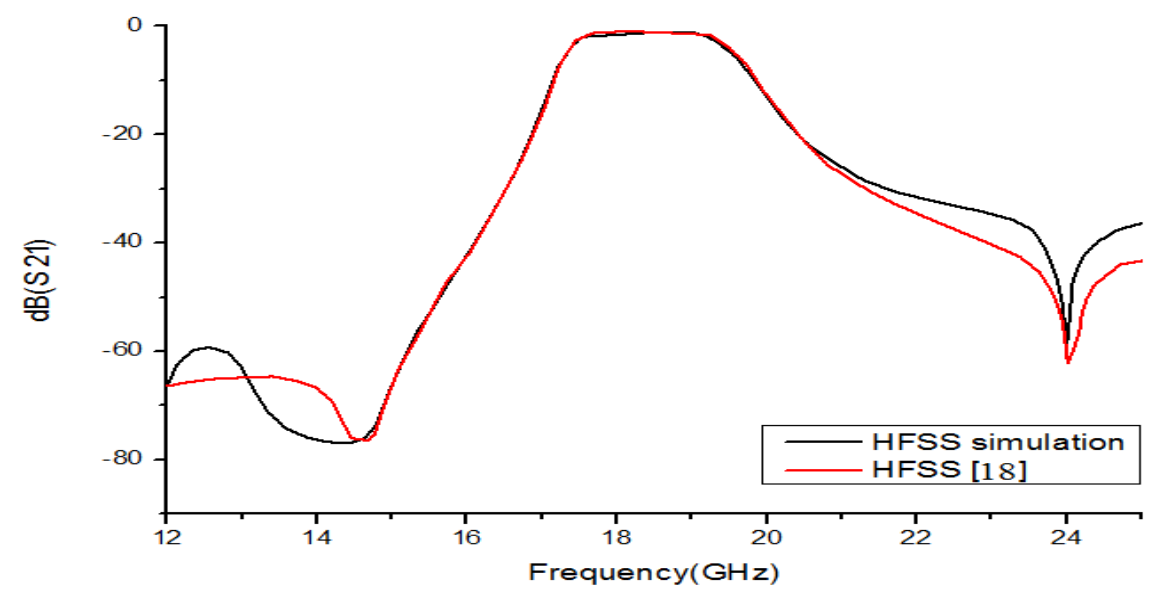

(a)

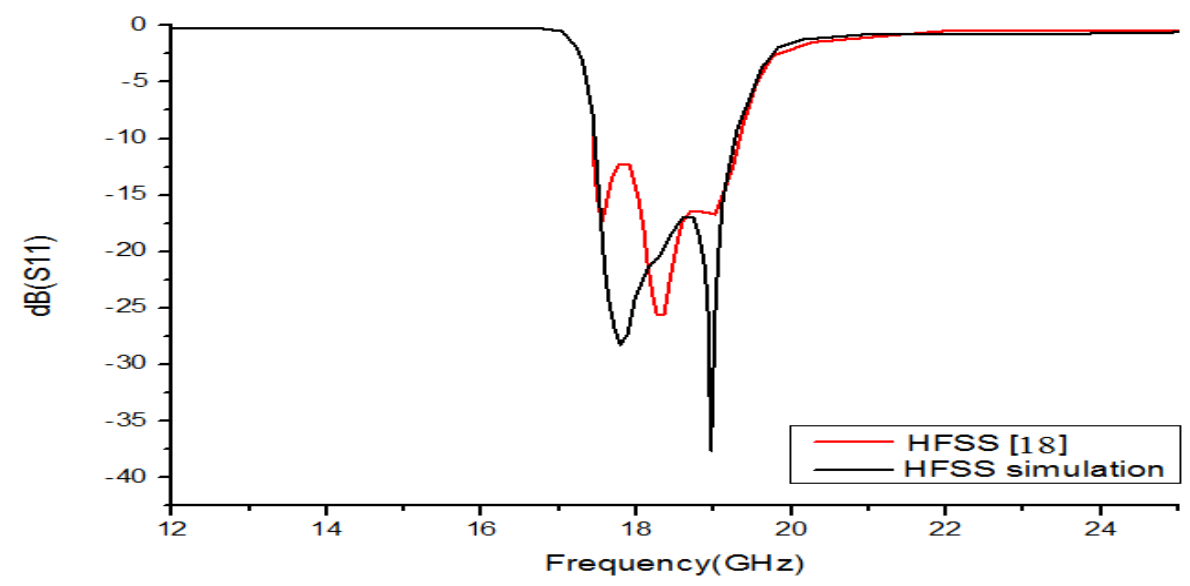

(b)

Fig. 22. Frequency response of SIW bandpass filter iris with high rejection. (a) Transmission coefficient S21 as a function of frequency. (b) Reflection coefficient S11 as a function of frequency.

The results simulated by HFSS are in good agreement with the results in [18]. The results simulated by HFSS shows that the full frequency passband is from 17.3 to $19.3 \mathrm{GHz}$. the center frequency $\mathrm{f}_{0}=18.3 \mathrm{GHz}$, the absolute bandwidth $2 \mathrm{GHz}$ and the relative bandwidth $\mathrm{FBW}=10.9 \%$. The insertion loss around $18.3 \mathrm{GHz}$ is approximately $1.35 \mathrm{~dB}$, the return loss in the passband is better than $15 \mathrm{~dB}$, with high rejection of $-57.88 \mathrm{~dB}$ at the frequency $24.07 \mathrm{GHz}$.

This filter have a small size can be directly integrated with other circuits. This makes them favorable for the applications of multimedia services.

\section{CONCLUSION}

In this work, a bandpass SIW filter with high rejection was presented for K-band applications. Which are designed by three steps, the first is the design of the SIW bandpass filter in the K-band based on the iris topology, the second is the design of cavity resonator SIW bandstop and finally combine the two structures for to have a SIW bandpass filter in the K-band with high rejection.

The simulated results of this filter have shown that the passband is from 17.3 to $19.3 \mathrm{GHz}$. the center frequency $\mathrm{f}_{0}=18.3 \mathrm{GHz}$, the absolute bandwidth $2 \mathrm{GHz}$ and the relative bandwidth $\mathrm{FBW}=10.9 \%$. The insertion loss around $18.3 \mathrm{GHz}$ is approximately $1.35 \mathrm{~dB}$, the return loss in the 
passband is better than $15 \mathrm{~dB}$, with high rejection of $-57.88 \mathrm{~dB}$ at the frequency $24.07 \mathrm{GHz}$.

These filters are easy for integration with other planar circuit compared by using conventional waveguide. The design method is discussed; the results from our analysis are in good agreement with previous research done on this topic. These bandpass SIW filter with high rejection is suitable for practical applications.

\section{REFERENCES}

[1] Garima Pathak, "Substrate integrated waveguide based RF MEMS cavity filter," International Journal of Recent Technology and Engineering, vol. 2, pp. 46-49, 2013.

[2] Bouchra Rahali and Mohammed Feham, "Design of K-Band substrate integrated waveguide coupler, circulator and power divider," International Journal of Information and Electronics Engineering, vol. 4, no. 1, pp. 47-53, 2014.

[3] D.V.B.Murthy, Alonso Corona Chávez and José L. Olvera-Cervantes, "Design and development of miniaturized filters using substrate integrated semicircular cavities," International Journal of Microwave and Optical Technology, vol. 5, no. 5, pp. 287-291, 2010.

[4] Yasser Arfat, Sharad P. Singh, Sandeep Arya, Saleem Khan, "Modelling, design and parametric considerations for different dielectric materials on substrate integrated waveguide," Wseas Transactions on Communications, vol. 13, pp. 94-98, 2014.

[5] B. H. Ahmad, Siti Sabariah Sabri and A. R. Othman, "Design of a compact X-Band substrate integrated waveguide directional coupler,” International Journal of Engineering \& Technology, vol. 5, no 2, pp. 1905-1911, 2013.

[6] Yongmao Huang, Zhenhai Shao and Lianfu Liu, "A substrate integrated waveguide bandpass filter using novel defected ground structure shape,” Progress In Electromagnetics Research, vol. 135, pp. 201-213, 2013.

[7] Damou Mehdi, Nouri Keltouma, Taybe Habib Chawki Bouazza and Meghnia.Feham, "Design of substrat integerated waveguide bandpass filter of SCRRs in the microstrip line," International Journal of Engineering Research and General Science, vol. 2, pp. 302-314, 2014.

[8] M. N. Husain, G. S. Tan, K. S. Tan, "Enhanced performance of substrate integrated waveguide bandstop filter using circular and radial cavity resonator," International Journal of Engineering and Technology, vol. 6, no. 2, pp. 1268-1277, 2014.

[9] K. Cheraghi, R. Sarraf Shirazi and Gh. Moradi, "Frequency sensitivity of a substrate integrated waveguide devices by finite element method," International Journal of Advanced Research in Electrical, Electronics and Instrumentation Engineering, vol. 2, pp. 4580- 4584, 2013.

[10] Pozar, David M., "Microwave engineering, fourth edition," John Wiley and Sons, 2012.

[11] Hemendra Kumar, Ruchira Jadhav and Sulabha Ranade, "A review on substrate integrated waveguide and its microstrip interconnect," Journal of Electronics and Communication Engineering, vol. 3, pp. 36-40, 2012.

[12] K. Nouri, M. Feham, Mehdi Damou and Tayeb Habib Chawki Bouazza, "Design of substrate integrated waveguide micro-wave planar directional coupler," International Journal of Scientific \& Engineering Research, vol. 5, pp. 1239$1242,2014$.

[13] Jia-Sheng Hong and M. J. Lancaster, “Microstrip filters for RF/Microwave applications,” John Wiley and Sons, 2001.

[14] Nouri Keltouma, Feham Mohammed and Adnan Saghir, "Design and characterization of tapered transition and inductive window filter based on substrate integrated waveguide technology (SIW)," International Journal of Computer Science Issues, vol. 8, no. 3, 2011.

[15] Woon-Gi Yeo, Tae-Yoon Seo, Jae W. Lee, and Choon Sik Cho, "H-Plane sectoral filtering horn antenna in PCB substrates using via fences at millimetre-wave," Proceedings of the 37th European Microwave Conference, pp. 818 $821,2007$.

[16] N. Marcuvitz, "Waveguide handbook," M.I.T. Rad. Lab. Ser, vol. 10. New York: McGraw-Hill, 1951.

[17] D. Zelenchuk, V. Fusco, "Low insertion loss substrate integrated waveguide quasi-elliptic filters for V-band wireless personal area network applications," IET Microwaves, Antennas and Propagation, vol. 5, no. 8, pp. 921-927, 2010.

[18] B. Zheng, Z. Zhao, and Y. Lv, "A K-Band SIW filter with bypass coupling substrate integrated circular cavity (SICC) to improved stopband performance for satellite communication," Progress In Electromagnetics Research C, vol. 17, pp. 95-104, 2010. 